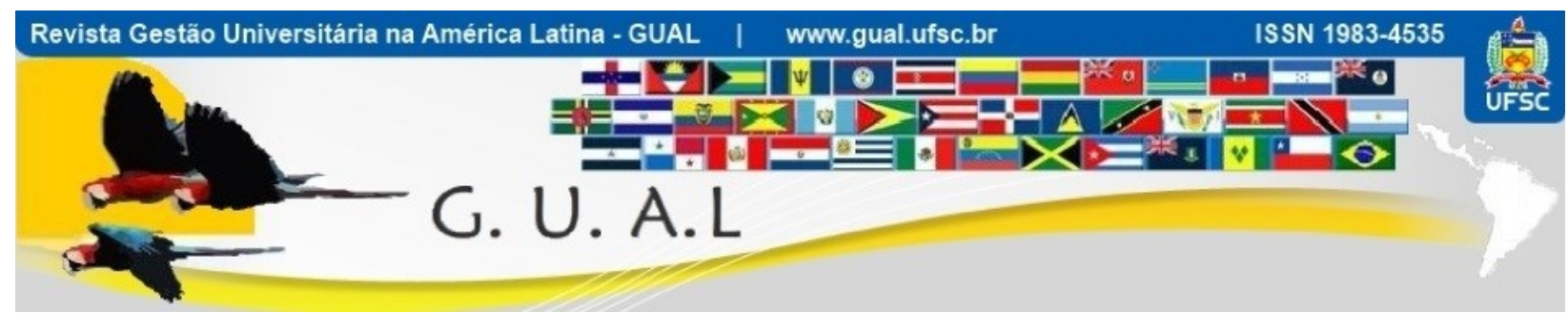

DOI: http://dx.doi.org/10.5007/1983-4535.2017v10n1p256

\title{
A POLÍTICA DE COTAS SOCIAIS PARA O ACESSO AO ENSINO SUPERIOR: O CASO DAS UNIVERSIDADES FEDERAIS MINEIRAS
}

\author{
POLITICS OF SOCIAL QUOTAS FOR ACCESS TO HIGHER EDUCATION: CASE \\ OF FEDERAL UNIVERSITIES OF THE MINAS GERAIS
}

Sabrina Olimpio Caldas de Castro, Mestranda

Universidade Federal de Viçosa - UFV sabrinadekastro@,hotmail.com

Fernanda Maria de Almeida, Doutora Universidade Federal de Viçosa - UFV fernanda.almeida@ufv.br

Rafael Morais Pereira, Mestrando Universidade de São Paulo - USP rafael.morais12@hotmail.com

Humberto Rodrigues Marques, Mestrando Universidade Federal de Lavras - UFLA hbetorm@hotmail.com

José Estevam Chaves Braga, Graduado Escola de Estudos Superiores de Viçosa - ESUV jestevamchaves@gmail.com

Recebido em 30/abril/2016

Aprovado em 18/novembro/2016

Sistema de Avaliação: Double Blind Review

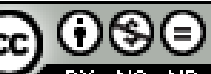

Esta obra está sob uma Licença Creative Commons Atribuição-Uso. 


\title{
RESUMO
}

O presente estudo objetivou verificar se há diferença no desempenho acadêmico entre alunos que tiveram e os que não tiveram acesso às Universidades Federais mineiras via política de cotas sociais. Para tanto, considerou-se todos os cursos dessas universidades que realizaram o Exame Nacional de Desempenho dos Estudantes em 2013. Realizou-se uma análise descritiva para caracterizar o grupo de formandos, considerando como variáveis o tipo de escola e renda familiar. Posteriormente, realizou-se uma (i) análise para aferir se o rendimento no Enade dos alunos que cursaram o ensino médio em escolas públicas se difere daqueles advindos de escolas particulares e; (ii) se o rendimento dos alunos ingressantes na universidade por meio das cotas sociais é inferior ao rendimento dos demais alunos; por meio da representação gráfica, da análise da estatística descritiva dos dados e do teste de diferença entre médias independentes. Identificou-se que o número de alunos oriundos de escola pública e com baixa renda é inferior ao número de alunos provenientes de escolas privadas nos cursos analisados. Além disso, os resultados demonstraram que não há uma diferença estatisticamente significativa entre o desempenho das categorias consideradas.

Palavras-chave: Ações afirmativas. Cotas sociais. Ensino Superior.

\begin{abstract}
This study aimed to observe the differences in academic performance between students who had and those who did not have access to Federal Universities of the Minas Gerais via social policy quotas. Therefore, it considered all the courses of this university who performed the National Examination Performance of Students in 2013. We conducted a descriptive analysis to characterize the group of students, considering variables as the type of school and family income. Subsequently took place one (i) analysis to assess whether the income in Enade of students who attended high school in public schools differs from those coming from private schools and; (ii) the performance of students entering the university through social shares is less than the performance of other students; graphical representation, descriptive statistics of the data analysis and test of difference between independent averages. It was identified that the number of students from public school and low-income is less than the number of students from private schools in the courses analyzed. Moreover, the results showed that no statistically significant difference between the performance of the categories considered.
\end{abstract}

Key words: Affirmative action. Social quotas. Higher Education. 


\section{INTRODUÇÃO}

As ações afirmativas referem-se às políticas públicas, privadas ou realizadas em parceria público-privada, destinadas ao combate à desigualdade de grupos vulneráveis a sofrer determinado tipo de descriminação. A prática destas ações iniciou-se na Índia, no entanto, o termo que as designa emergiu nos Estados Unidos na década de 1960, em virtude da exigência da sociedade para se estabelecer critérios equitativos na reestruturação dos Estados de direito (MOEHLECKE, 2002; CESAR, 2003; BELLO, 2005; LAGO et al., 2014).

O sistema de cotas constitui no mecanismo mais praticado de ação afirmativa. No Brasil, há existência de cotas de participação em alguns campos da sociedade, como as cotas destinadas a negros, pardos e portadores de deficiência física em concursos públicos e ao ingresso das mulheres na esfera política. No entanto, segundo Motta e Lopes (2012), a discussão referente às cotas para acesso ao ensino superior destaca-se como um dos mais intensos e polêmicos debates no meio social e acadêmico.

O assunto atingiu seu ápice em 2012. Em agosto desse ano, a presidente Dilma Rousseff sancionou a Lei 12.711, conhecida como Lei de Cotas Sociais. Esta lei torna obrigatório que até agosto de 2016 todas as instituições federais de ensino reservem no mínimo 50\% das vagas para estudantes que cursaram todo o ensino médio em escolas da rede pública.

A favor das cotas destinadas aos estudantes provenientes de escolas públicas, argumenta-se que estes alunos encontram-se em desvantagem ao tentarem ingressar nas universidades públicas brasileiras. Esta desvantagem estaria ligada ao fato destes estudantes não terem acesso a uma preparação que permita concorrer em condições equitativas com alunos provenientes da rede particular de ensino.

Neste aspecto, o ensino fundamental e médio da rede pública brasileira é extremamente frágil, resultando na sub-representação das classes com menor poder aquisitivo no ensino superior (MOTTA; LOPES, 2012). Em meio a tal cenário de desigualdades, a adoção da política de cotas sociais para o acesso às universidades públicas emerge como mecanismo constitucional, apto a consolidar o direito à educação, ao proporcionar o acesso ao ensino de qualidade a grupos específicos.

No entanto, segundo Frias (2012) alguns críticos a esta modalidade de ação afirmativa argumentam que os alunos que ingressam por meio das cotas sociais ocasionarão retrocesso no desempenho das instituições federais de ensino superior. Segundo os estudiosos adeptos a 


\section{A POLÍTICA DE COTAS SOCIAIS PARA O ACESSO AO ENSINO SUPERIOR: O CASO DAS

esta argumentação, o atraso seria ocasionado pelo fato destes estudantes possuírem desempenho inferior em relação aos alunos provenientes da rede privada de ensino, demandando maior atenção do corpo docente e resultando na necessidade dos professores ministrarem conteúdos básicos que apenas foram lecionados aos alunos provenientes de escolas da rede privada.

Apesar das controvérsias relacionadas ao déficit educacional dos alunos provenientes da rede pública de ensino, considera-se que as cotas sociais desempenham papel importante na redução das desigualdades existentes no acesso ao ensino superior. Neste sentido,o presente estudo buscou responder a seguinte questão: qual o impacto da adoção da política de cotas sociais no acesso às universidades federais mineiras e no desempenho acadêmico destas instituições?

A fim de responder esta questão de pesquisa, este estudo teve como objetivo geral verificar se há diferença no desempenho acadêmico entre alunos que tiveram e os que não tiveram acesso às Universidades Federais mineiras via política de cotas sociais. Para tanto, especificamente, verificou-se (i) aspectos socioeconômicos dos formandos das universidades federais mineiras no ano de 2013 que realizaram o Exame Nacional de Desempenho dos Estudantes (Enade), (ii)se o rendimento no Enade dos alunos ingressantes no ensino superior que cursaram o ensino médio em escolas públicas se difere daqueles advindos de escolas particulares, (iii) se o rendimento no Enade dos alunos ingressantes na universidade por meio das cotas sociais é inferior ao rendimento dos demais alunos.

O Enade visa analisar o aprendizado fornecido ao aluno e o efeito do curso nesse processo. Para atingir esse objetivo, cada curso é avaliado em um intervalo de três anos. Este exame gera uma série de dados relacionados com o desempenho dos estudantes que são devolvidos à instituição em forma de relatórios, os quais também são disponibilizados no portal do Instituto Nacional de Estudos e Pesquisas Educacionais Anísio Teixeira (INEP).

Ao mesmo tempo, o Enade conta com um instrumento de coleta de informações, de caráter obrigatório, intitulado Questionário do Estudante, que tem por objetivo subsidiar a construção do perfil socioeconômico dos estudantes. Estes dados são disponibilizados nos relatórios, concomitantemente aos dados do desempenho dos estudantes no exame. Os dados mais recentes disponíveis no portal do INEP referem-se ao exame aplicado no ano de 2013. Por tal fato, optou-se abordar os cursos avaliados no referido ano, os quais conferiram diploma de bacharel em Agronomia, Biomedicina, Educação Física, Enfermagem, Farmácia, 
Fisioterapia, Fonoaudiologia, Medicina, Medicina Veterinária, Nutrição, Odontologia, Serviço Social e Zootecnia.

Em relação à justificativa deste trabalho, destaca-se sua contribuição para o arcabouço da temática de políticas de cotas sociais e seus possíveis efeitos na redução das desigualdades existentes no acesso ao ensino superior público e no desempenho das instituições. Trata-se de uma temática que incita discussões e que há carência de estudos práticos que contextualizem o atual cenário de transição nas políticas de acesso ao ensino superior.

Este estudo contempla, além desta introdução, cinco seções. Inicialmente, apresenta-se uma revisão teórica, subdivida em dois tópicos. O primeiro destina-se à abordagem histórica e conceitual das ações afirmativas, enquanto o segundo aborda especificamente as cotas para o acesso ao Ensino Superior no Brasil. Na sequência, apresentam-se os procedimentos metodológicos adotados na pesquisa, com detalhamento dos métodos utilizados. Por fim, temse a análise e discussão dos resultados, à luz da revisão teórica, bem como as considerações finais e referências.

\section{AÇÕES AFIRMATIVAS: ABORDAGEM HISTÓRICA E CONCEITUAL}

A desigualdade caracteriza-se pela posição desvantajosa em que determinados grupos se encontram em relação a outros e resulta das irregularidades ocorridas ao longo da história. Esse fenômeno acarreta consequências negativas para os grupos atingidos, dentre as quais está a exclusão social. Em virtude deste efeito, o Estado, concomitante a setores da administração pública indireta, passou a implantar políticas que favorecem pessoas pertencentes a grupos discriminados (MOTTA; LOPES, 2012).

Essa prática iniciou-se na Índia, em 1950. Nessa década, inseriu-se na Constituição do país um dispositivo que permitia a adoção de ações destinadas a atenuar as disparidades resultantes do regime de divisão das sociedades em castas, em função de aspectos étnicos e socioeconômicos dos indianos (BELLO, 2005; SILVA; SILVA, 2012). O termo ação afirmativa, atualmente utilizado para nomear ações em prol das populações desfavorecidas, emergiu na década seguinte nos Estados Unidos (MOEHLECKE, 2002; BELLO, 2005; LAGO et al., 2014). As ações afirmativas normalmente possuem caráter provisório e são definidas, conforme Gomes (2001), como: 


\section{A POLÍTICA DE COTAS SOCIAIS PARA O ACESSO AO ENSINO SUPERIOR: O CASO DAS \\ UNIVERSIDADES FEDERAIS MINEIRAS \\ DOI: http://dx.doi.org/10.5007/1983-4535.2017v10n1p256}

(...) um conjunto de políticas públicas e privadas de caráter compulsório, facultativo ou voluntário, concebidas com vistas ao combate à discriminação racial, de gênero e de origem nacional, bem como para corrigir os efeitos presentes da discriminação praticada no passado, tendo por objetivo a concretização do ideal de efetiva igualdade de acesso a bens fundamentais como a educação e o emprego (GOMES, 2001, p. 40).

A adoção de ações com a finalidade de atenuar disparidades se propagou em diversas regiões do mundo. Na Europa, recebeu a nomenclatura de "ação discriminativa positiva", sendo inserida em 1982 no primeiro Programa de Ação para a Igualdade de Oportunidades da Comunidade Econômica Europeia. Nos diferentes contextos em que foram adotadas, as ações afirmativas assumiram caráter voluntário, obrigatório ou misto, resultando de ações governamentais ou de entes privados (MOEHLECKE, 2002).

As ações afirmativas possuem áreas distintas de implementação, dentre as quais é possível citar as direcionadas aos cargos públicos eletivos, ao mercado de trabalho e à concessão de isenções fiscais pelo poder público (BELLO, 2005). Tais ações buscam, principalmente, proporcionar a todos na sociedade condições de competir igualmente pelo acesso aos meios fundamentais, como emprego e educação (JONES, 1993; CROSBY; CORDOVA, 1996; GOMES, 2001; SILVA; SILVA, 2012).

O primeiro registro encontrado referente à adoção de ações afirmativas no Brasil remete ao ano 1968 (MOEHLECK, 2002). Nessa data, discutiu-se entre técnicos do Ministério do Trabalho e do Tribunal Superior do trabalho a necessidade de elaborar uma lei que tornasse obrigatório às empresas do setor privado contratar uma porcentagem mínima de empregados negros.

Esta lei propunha atuar como mecanismo redutor da discriminação no campo trabalhista, mas não chegou a ser elaborada. Entretanto, estabeleceu o marco inicial das discussões em prol de ater-se aos grupos desfavorecidos, constituídos em função das irregularidades ocorridas ao longo da trajetória histórica brasileira, que desde os primórdios favoreceu minorias elitizadas.

Transcorridas duas décadas, constituiu-se efetivamente a primeira ação afirmativa em solo brasileiro. Apenas ao se estabelecer na Constituição da República Federativa do Brasil em 1988 a reserva de vagas para deficientes físicos no mercado de trabalho, estabeleceu-se de fato a primeira ação afirmativa em prol de um grupo de brasileiros desfavorecidos (BRANDÃO, 2005). 
A ação afirmativa assumiu desenhos diferentes nos países em que foi adotada, sendo o sistema de cotas o mais conhecido entre os mecanismos praticados. O sistema de cotas é definido por Motta e Lopes (2012) como:

(...) políticas, geralmente temporárias, que dispensam tratamento preferencial às pessoas pertencentes à classe ou grupos minoritários, como forma de proporcionar o acesso às instituições educacionais e setores do mercado de trabalho, por meio de reserva de vagas, a fim de compensar os prejuízos sofridos por esta população ao longo da história. Trata-se de uma espécie de ação afirmativa que vem sendo aplicada em vários países, para corrigir as desigualdades existentes no meio social (MOTTA; LOPES, 2012, p. 6838).

O sistema educacional, notadamente o ensino superior, encontra-se entre as principais áreas contempladas por esta modalidade de ação afirmativa, resultando em divergências de opiniões no seio social. Neste sentido, o tópico seguinte destinou-se à abordagem específica da temática.

\section{COTAS PARA O ACESSO AO ENSINO SUPERIOR NO BRASIL}

A adoção do mecanismo de cotas para acesso às Instituições Públicas de Ensino Superior consiste em um tema que tem ocasionado divergências no meio social, tornando-se alvo de vários estudos de pesquisadores no âmbito acadêmico. A temática constituiu objeto de estudo de Moehlecke (2002), Leite (2011), Bezerra e Gurgel (2011), Frias (2012), Motta e Lopes (2012), Machado e Magaldi (2014), Lago et al. (2014) e Pinheiro (2014).

Os primeiros relatos referentes ao uso de ações afirmativas designadas para o ensino superior brasileiro remetem à adoção de cotas raciais para negros e indígenas em 2001, pela Universidade do Estado do Rio de Janeiro e pela Universidade do Norte Fluminense (LAGO et al., 2014). O assunto atingiu seu ápice em 2012, ano no qual no mês de abril o Supremo Tribunal Federal apreciou a adoção da política de cotas da Universidade de Brasília. Julgou-se constitucional o mecanismo da instituição de direcionar $20 \%$ das vagas para alunos negros e índios (FRIAS, 2012).

Em agosto do mesmo ano, a presidente Dilma Rousseff sancionou a Lei 12.711, conhecida como Lei de Cotas Sociais, tornando obrigatório que até agosto de 2016, todas as instituições federais de ensino reservem no mínimo 50\% das vagas para estudantes que cursaram todo o ensino médio em escolas da rede pública. Metade dessas vagas deve ser reservada aos estudantes cujas famílias possuem renda per capita de até um salário mínimo e meio. Ademais, dentro desses $50 \%$, as instituições deverão reservar um número de vagas para 


\section{A POLÍTICA DE COTAS SOCIAIS PARA O ACESSO AO ENSINO SUPERIOR: O CASO DAS \\ UNIVERSIDADES FEDERAIS MINEIRAS \\ DOI: http://dx.doi.org/10.5007/1983-4535.2017v10n1p256}

candidatos autodeclarados negros, pardos e índios,em número mínimo àquele relacionado ao percentual de negros, pardos e índios da Unidade da Federação onde está instalada, segundo o último censo do Instituto Brasileiro de Geografia e Estatística (IBGE). O restante das vagas referentes à cota de 50\% das vagas dos cursos será direcionado aos estudantes que cursaram o ensino médio integralmente na rede pública.

Por se constituir como uma forma de ação afirmativa, a política de cotas estabelecida pela Lei 12.711 possui caráter provisório e avaliativo. Perpassado uma década de sua sanção, seus impactos positivos e negativos na educação superior ainda devem ser amplamente avaliados. Esta análise permitirá ao Estado avaliar se os objetivos iniciais foram alcançados e quais os procedimentos podem ser adotados para aperfeiçoamento da proposta inicial.

A aprovação desta lei transforma as universidades públicas em instituições mais equitativas e heterogêneas (MACHADO; MAGALDI, 2014). Desta forma, passa a representar a sociedade brasileira como um todo, deixando de privilegiar uma parcela que por séculos apresentou posição vantajosa atribuída à sua condição social.

No entanto, segundo Motta e Lopes (2012), alguns críticos a esta modalidade de ação afirmativa argumentam que os alunos que ingressam por meio das cotas sociais ocasionarão retrocesso no nível de ensino das instituições federais de ensino superior. Segundo os estudiosos adeptos a esta argumentação, o atraso seria ocasionado pelo fato destes estudantes demandarem maior atenção do corpo docente, levando os professores a ministrar conteúdos básicos que apenas foram lecionados aos alunos provenientes de escolas da rede privada.

Frias (2012) contrapõe este argumento ao defender que o objetivo primordial da universidade pública consiste em promover a justiça social, ou seja, viabilizar a igualdade equitativa de oportunidades. $\mathrm{O}$ autor enfatiza que embora a busca pela excelência acadêmica possua significância, esta pode ser sacrificada em prol do estabelecimento da justiça social. Neste sentido, mesmo por meio da comprovação da redução nos indicadores acadêmicos e científicos em função da adoção das cotas sociais, tal constatação seria insuficiente para evidenciar que esta ação afirmativa é injusta.

A educação constitui um direito fundamental disposto na Constituição da República Federativa do Brasil (1988), sendo de competência do Estado promovê-la e estender seu acesso a todos. Nesse sentido, a educação deve possibilitar o desenvolvimento da personalidade humana, permitindo ao indivíduo conquistar sua liberdade e ascensão social por meio do conhecimento advindo do ensino (MOTTA; LOPES, 2012). 


\section{A POLÍTICA DE COTAS SOCIAIS PARA O ACESSO AO ENSINO SUPERIOR: O CASO DAS \\ UNIVERSIDADES FEDERAIS MINEIRAS \\ DOI: http://dx.doi.org/10.5007/1983-4535.2017v10n1p256}

No atual cenário de desigualdades existentes no Brasil, a adoção da política de cotas sociais para o acesso às universidades públicas emerge como mecanismo apto a ampliar o acesso à educação superior e a contribuir para a constituição de uma sociedade com menores níveis de desigualdades sociais. Trata-se de uma medida constitucional que busca consolidar o direito à educação, ao proporcionar o acesso ao ensino de qualidade a grupos específicos.

Reformular o ensino básico e médio a fim de oferecer ensino de qualidade aos alunos da rede pública reduziria efetivamente as desigualdades existentes no acesso ao ensino superior. Contudo, por se tratar de uma medida gradativa e de longo prazo, as cotas sociais ganham considerável importância para amenizar as desigualdades. Em tais circunstâncias, as cotas sociais são mecanismos hábeis a proporcionar benefícios imediatos para viabilizar o acesso à educação superior aos economicamente desfavorecidos, incapazes de competir com candidatos oriundos da rede privada em condições equitativas (MOTTA; LOPES, 2012).

Com base nos conceitos e argumentos dos distintos autores abordados neste referencial teórico, buscou-se discutir o impacto da adoção da política de cotas sociais para o acesso às universidades federais mineiras. Os procedimentos metodológicos adotados para o alcance deste objetivo encontram-se dispostos no tópico subsequente.

\section{METODOLOGIA}

Este tópico destina-se à apresentação dos procedimentos metodológicos adotados para a realização deste estudo, os quais se encontram dispostos em três tópicos: caracterização da pesquisa, método utilizado para atender o objetivo específico (i) e método utilizado para atender o objetivo específico (ii) e (iii).

\subsection{CARACTERIZAÇÃO DA PESQUISA}

Para o alcance do objetivo proposto, considerou-se todos os cursos das Universidades Federais do estado de Minas Gerais que realizaram o ENADE no ano de 2013, último ano que possui dados disponibilizados no site do INEP. Considerou-se este estado em virtude de Minas Gerais possuir o maior número de instituições federais. Atualmente, existem onze dessas instituições no estado, sendo estas as Universidades Federais: de Itajubá (UNIFEI), de Juiz de Fora (UFJF), de Lavras (UFLA), de Minas Gerais (UFMG), de Ouro Preto (UFOP), de Uberlândia (UFU), de Viçosa, (UFV), de São João del-Rei (UFSJ), do Triângulo Mineiro (UFTM), de Alfenas (UNIFAL) e dos Vales do Jequitinhonha e Mucuri (UFVJM). 


\section{A POLÍTICA DE COTAS SOCIAIS PARA O ACESSO AO ENSINO SUPERIOR: O CASO DAS \\ UNIVERSIDADES FEDERAIS MINEIRAS \\ DOI: http://dx.doi.org/10.5007/1983-4535.2017v10n1p256}

Dentre estas universidades, desconsiderou-se apenas a UNIFEI para a realização deste estudo, em virtude da instituição não ter tido cursos avaliados no ano de 2013. Para as demais, considerou-se os cursos avaliados oferecidos em todos os campi. No Quadro 1 apresenta-se os cursos analisados das referidas instituições.

\begin{tabular}{|c|c|c|c|c|c|}
\hline & Curso & IFES & & Curso & IFES \\
\hline 1 & Educação Física & UFJF & 37 & Fisioterapia & UFMG \\
\hline 2 & Enfermagem & UFJF & 38 & Fonoaudiologia & UFMG \\
\hline 3 & Fisioterapia & UFJF & 39 & Medicina & UFMG \\
\hline 4 & Farmácia & UFJF & 40 & Medicina Veterinária & UFMG \\
\hline 5 & Medicina & UFJF & 41 & Nutrição & UFMG \\
\hline 6 & Nutrição & UFJF & 42 & Odontologia & UFMG \\
\hline 7 & Odontologia & UFJF & 43 & Tecnologia em Radiologia & UFMG \\
\hline 8 & Serviço Social & UFJF & 44 & Agronomia & UFMG \\
\hline 9 & Agronomia & UFU & 45 & Zootecnia & UFMG \\
\hline 10 & Biomedicina & UFU & 46 & Agronomia & UFV \\
\hline 11 & Educação Física & UFU & 47 & Educação Física & UFV \\
\hline 12 & Enfermagem & UFU & 48 & Enfermagem & UFV \\
\hline 13 & Fisioterapia & UFU & 49 & Medicina Veterinária & UFV \\
\hline 14 & Medicina & UFU & 50 & Nutrição & UFV \\
\hline 15 & Medicina Veterinária & UFU & 51 & Zootecnia & UFV \\
\hline 16 & Nutrição & UFU & 52 & Tecnologia em Gestão Ambiental & UFV \\
\hline 17 & Odontologia & UFU & 53 & Agronomia & UFVJM \\
\hline 18 & Serviço Social & UFU & 54 & Enfermagem & UFVJM \\
\hline 19 & Educação Física & UFOP & 55 & Farmácia & UFVJM \\
\hline 20 & Farmácia & UFOP & 56 & Fisioterapia & UFVJM \\
\hline 21 & Medicina & UFOP & 57 & Nutrição & UFVJM \\
\hline 22 & Nutrição & UFOP & 58 & Odontologia & UFVJM \\
\hline 23 & Serviço Social & UFOP & 59 & Zootecnia & UFVJM \\
\hline 24 & Agronomia & UFLA & 60 & Serviço Social & UFVJM \\
\hline 25 & Educação Física & UFLA & 61 & Biomedicina & UFTM \\
\hline 26 & Medicina Veterinária & UFLA & 62 & Educação Física & UFTM \\
\hline 27 & Nutrição & UFLA & 63 & Medicina & UFTM \\
\hline 28 & Zootecnia & UFLA & 64 & Nutrição & UFTM \\
\hline 29 & Zootecnia & UFSJ & 65 & Serviço Social & UFTM \\
\hline 30 & Enfermagem & UFSJ & 66 & Biomedicina & UNIFAL \\
\hline 31 & Farmácia & UFSJ & 67 & Enfermagem & UNIFAL \\
\hline 32 & Medicina & UFSJ & 68 & Farmácia & UNIFAL \\
\hline 33 & Agronomia & UFSJ & 69 & Fisioterapia & UNIFAL \\
\hline 34 & Educação Física & UFMG & 70 & Nutrição & UNIFAL \\
\hline 35 & Enfermagem & UFMG & 71 & Odontologia & UNIFAL \\
\hline 36 & Farmácia & UFMG & & & \\
\hline
\end{tabular}

Quadro 1 Cursos e IFES analisados.

Fonte: Dados da pesquisa, a partir de informações disponíveis na plataforma do INEP. 


\section{A POLÍTICA DE COTAS SOCIAIS PARA O ACESSO AO ENSINO SUPERIOR: O CASO DAS \\ UNIVERSIDADES FEDERAIS MINEIRAS \\ DOI: http://dx.doi.org/10.5007/1983-4535.2017v10n1p256}

Para o desenvolvimento do estudo, utilizou-se uma abordagem quantitativa. Segundo Roesh (1999, p. 122), esse "método enfatiza a utilização de dados padronizados que permitem ao pesquisador elaborar sumários, comparações e generalizações".

O levantamento de dados foi obtido por meio de dados secundários divulgados nos relatórios dos cursos que realizaram o ENADE em 2013, disponibilizados INEP. Nestes relatórios são disponibilizadas informações referentes ao questionário socioeconômico aplicado juntamente com a avaliação, além de dados relacionados ao desempenho dos estudantes no exame.

\subsection{MÉTODO UTILIZADO PARA ATENDER O OBJETIVO ESPECÍFICO (I)}

Com o desígnio de atender ao primeiro objetivo específico, que consiste em analisar aspectos socioeconômicos dos formandos das universidades federais mineiras no ano de 2013 que realizaram o Enade, realizou-se uma análise descritiva dos formandos dos cursos amostrados.

O tipo de escola em que os formandos cursaram o ensino médio consistiu na primeira variável considerada. Para tanto, considerou-se três categorias de análise. A categoria "somente em pública" engloba os alunos que cursaram todo o ensino médio em escolas da rede pública. Semelhantemente, a categoria "somente em privada" conglomera os alunos que cursaram todo este período em escolas da rede privada. A terceira categoria intitulada "outros" denomina uma minoria que cursou o ensino médio parcialmente na rede pública e na privada. Para complementar a análise da variável, realizou-se a distribuição dos alunos das categorias "somente pública" e "somente privada" nos quinze cursos avaliados pelo ENADEem 2013, com o intuito de aferir a maneira como os alunos encontram-se distribuídos nos cursos.

Posteriormente, analisou-se a variável renda. Para tanto, realizou-se a análise da renda familiar dos estudantes. Em seguida, realizou-se o levantamento de quantos alunos de cada um dos quinze cursos considerados na amostra possuíam renda familiar de até um salário mínimo e meio.

\subsection{MÉTODO UTILIZADO PARA ATENDER OS OBJETIVOS ESPECÍFICOS (II) E (III)}

Para atingir o segundo objetivo específico, que consiste em analisar se o rendimento no Enade dos alunos ingressantes no ensino superior que cursaram o ensino médio em escolas 


\section{A POLÍTICA DE COTAS SOCIAIS PARA O ACESSO AO ENSINO SUPERIOR: O CASO DAS

públicas se difere daqueles advindos de escolas particulares, realizou-se a análise entre a categoria "pública", que designa os estudantes que cursaram todo o ensino médio em escolas da rede pública e a categoria "privada",que se refere aos alunos que cursaram todo o ensino médio em escolas da rede privada.

Já para atingir o objetivo específico de aferir se o rendimento no Enade dos alunos ingressantes na universidade por meio das cotas sociais é inferior ao rendimento dos demais alunos, considerou-se outras duas categorias. A categoria "cotistas" designa os alunos que ingressaram na universidade pública por meio das cotas destinadas aos alunos que cursaram todo o ensino médio em escola pública ou em escola privada por meio da concessão de bolsas, enquanto a categoria "não cotistas" se refere aos alunos que não utilizaram nenhum tipo de cota para ingressar na universidade pública.

Foram calculadas as notas médias das categorias de alunos por curso. Inicialmente, realizou-se a análise da estatística descritiva dos dados, calculando para cada uma das categorias definidas o número de observações, a média, o desvio padrão e a nota mínima e máxima, utilizando o programa estatístico Stata ${ }^{\circledR}$ Statistics/Data Analysis 11.2.

Este mesmo programa estatístico foi utilizado para realizar o teste de diferença entre médias independentes com os dados coletados. Este método propõe a comparação entre grupos distintos, ou seja, amostras independentes que ocorrem, segundo Witte e Witte (2005, p. 252), quando "as observações em uma amostra não estiverem em pares com as observações na outra amostra, em uma base de uma para uma".

O teste buscou comparar as notas médias nos cursos das categorias consideradas. Neste teste estatístico a hipótese nula presume que não existe diferença entre as médias populacionais. Já a hipótese alternativa, prevê que há diferença entre as médias amostrais. Sendo assim:

$$
\left\{\begin{array}{l}
\mathrm{H} 0: \mu_{1=} \mu_{2} \\
\mathrm{H} 1: \mu_{1 \neq} \mu_{2}
\end{array}\right.
$$

Para a realização do primeiro teste consideraram-se as seguintes informações: média dos estudantes provenientes de escola privada $\left(\overline{\mathrm{X}}_{1}\right)$, com desvio padrão $\mathrm{S}_{1}$ e a média dos estudantes provenientes de escola pública $\left(\overline{\mathrm{X}}_{2}\right)$, com desvio padrão $\mathrm{S}_{2}$. Semelhantemente, no segundo teste utilizou-se a média dos estudantes que utilizaram cotas destinadas aos alunos que cursaram todo o ensino médio em escola pública ou em privada com bolsa $\left(\overline{\mathrm{X}}_{3}\right)$, com 
desvio padrão $S_{3}$ e a média dos estudantes que não utilizaram nenhum tipo de cota para ingressar na universidade $\left(\mathrm{X}_{4}\right)$, com desvio padrão $\mathrm{S}_{4}$.

De posse dessas informações calculou-se a variância, elevando-se os desvios ao quadrado. Caso uma das variâncias amostrais seja mais que o dobro da outra, deve-se utilizar a equação (1), caso contrário, deve-se utilizar a equação (2), ambas expressas abaixo:

$$
\begin{aligned}
& S_{\bar{X}_{1}-\bar{X}_{2}}=\sqrt{\left(\frac{n_{1} S_{1}^{2}+n_{2} S_{2}^{2}}{n_{1}+n_{2}-2}\right)\left(\frac{n_{1}+n_{2}}{n_{1} n_{2}}\right)} \\
& S_{\bar{X}_{1}-\bar{X}_{2}}=\sqrt{\left(\frac{S_{1}^{2}}{n_{1}-1}\right)\left(\frac{S_{2}^{2}}{n_{2}-1}\right)}
\end{aligned}
$$

Posteriormente, a fim de avaliar a significância estatística, adotou-se um nível de confiança mínimo de $90 \%$ para a rejeição de $\mathrm{H}_{0}$.

\section{ANÁLISE E DISCUSSÃO DOS RESULTADOS}

A fim de atingir o objetivo proposto, esta seção apresenta os principais resultados alcançados a partir das análises obtidas. No primeiro tópico, cumpriu-se com o primeiro objetivo específico, aoanalisar aspectos socioeconômicos dos formandos das universidades federais mineiras no ano de 2013 que realizaram o Enade, por meio da realização de uma análise descritiva para caracterizar o grupo de formandos do ano de 2013. Enquanto no segundo tópico abordou-se o segundo e o terceiro objetivo específico, por meio da análise da estatística descritiva dos dados e de dois testes de diferença entre médias.

\subsection{ANÁLISE DESCRITIVA DA AMOSTRA DE FORMANDOS}

Com o desígnio de discutir o impacto das cotas sociais como mecanismo que viabiliza o acesso de estudantes economicamente desfavorecidos ao ensino superior, realizou-se uma análise descritiva dos formandos das universidades federais mineiras do ano de 2013. Os dados utilizados foram coletados nos relatórios dos cursos das dez universidades mineiras avaliadas pelo ENADE no ano considerado.

Primeiramente, realizou-se um levantamento do tipo de escola em que os formandos cursaram o ensino médio, considerando-se três categorias de análise. A categoria "somente em pública" engloba os alunos que cursaram todo o ensino médio em escolas da rede pública. Semelhantemente, a categoria "somente em privada" conglomera os alunos que cursaram todo este período em escolas da rede privada. A terceira categoria intitulada "outros" denomina 


\section{A POLÍTICA DE COTAS SOCIAIS PARA O ACESSO AO ENSINO SUPERIOR: O CASO DAS \\ UNIVERSIDADES FEDERAIS MINEIRAS \\ DOI: http://dx.doi.org/10.5007/1983-4535.2017v10n1p256}

uma minoria que cursou o ensino médio parcialmente na rede pública e na privada. Os resultados obtidos encontram-se evidenciados na Figura 1.

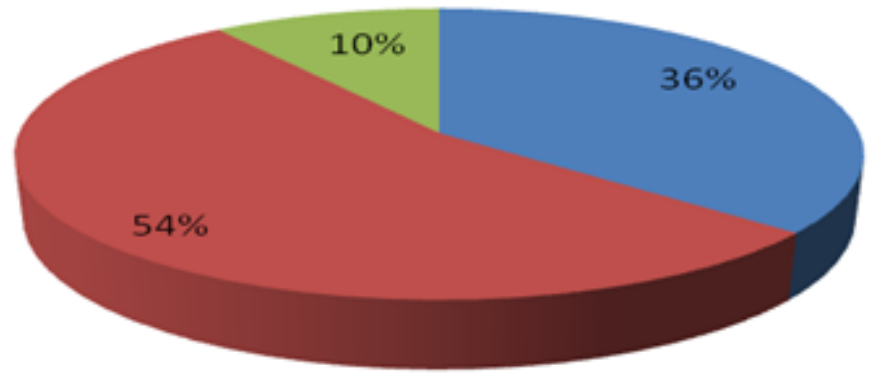

- Somente em pública

- Somente em privada

Eutos

Figura 1 Tipo de escola que os formandos cursaram o ensino médio.

Fonte: Dados da pesquisa, a partir de informações disponíveis na plataforma do INEP.

Nota-se que apenas $36 \%$ dos 4415 formandos considerados como amostra deste estudo cursaram todo o ensino médio em rede pública. Ao considerar que o número de alunos que concluem o ensino médio em escolas públicas supera o número de alunos que concluem o ensino médio em escolas privadas, identifica-se que a política de cotas sociais contribui para reduzir a desigualdade existente no acesso ao ensino superior, possibilitando que candidatos que não possuem preparação equitativa aos alunos oriundos da rede particular de ensino possam ter acesso às universidades públicas.

Motta e Lopes (2012) atribuem essa diferença ao grau de conhecimento destes dois grupos de alunos à destinação de um baixo ou irregular investimento do Poder Público para a educação. Segundo os autores, esta falta de investimento na educação básica e média acarreta na desmotivação dos professores da rede pública, os quais são submetidos a salários incompatíveis com sua jornada de trabalho. Além disso, os alunos da rede pública comparativamente possuem recursos educativos limitados e instalações físicas deficientes.

Além da diferença entre o número total de formandos que cursaram todo o ensino médio em escola pública e os que cursaram somente em escola privada, outro fator que se destaca consiste na alocação destes alunos nos cursos (Figura 2). 


\section{A POLÍTICA DE COTAS SOCIAIS PARA O ACESSO AO ENSINO SUPERIOR: O CASO DAS

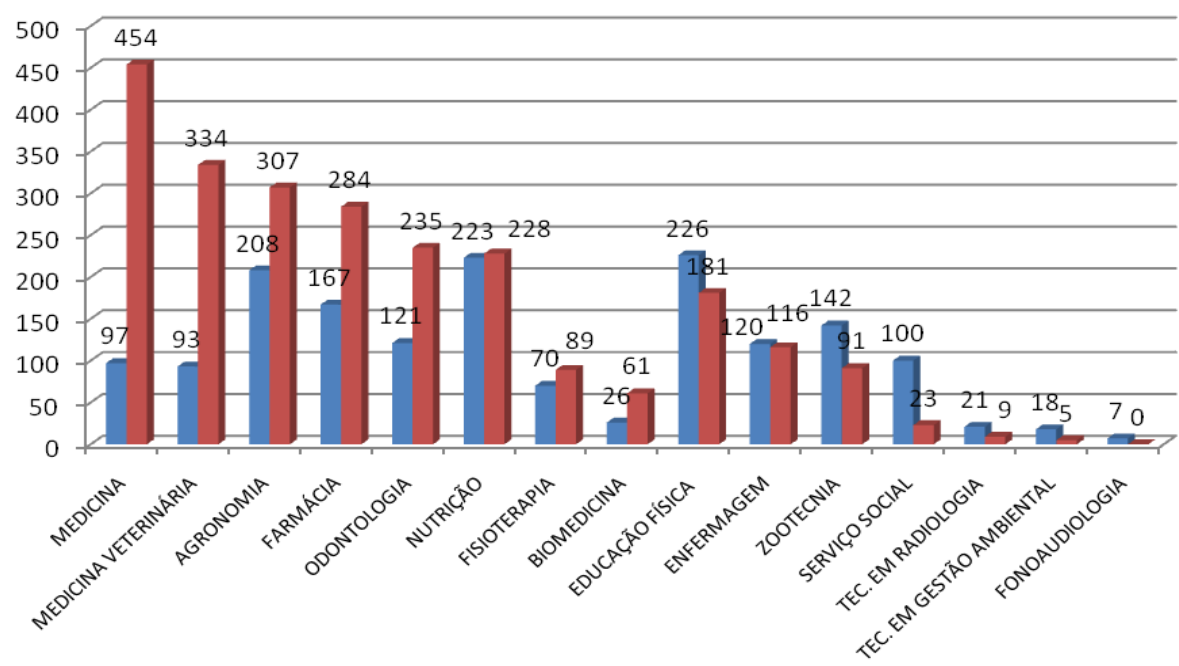

Figura 2 Alocação por curso dos alunos oriundos da rede pública e privada.

Fonte: Dados da pesquisa, a partir de informações disponíveis na plataforma do INEP.

Ao realizar a distribuição destes dois grupos de alunos entre os quinze cursos avaliados pelo ENADE em 2013, identifica-se uma nítida discrepância, principalmente entre o número de alunos das duas categorias consideradas nos cursos de medicina e medicina veterinária. Nestes cursos, o número de alunos provenientes de escolas privadas são 4,68 e 3,59 vezes maior que os alunos provenientes de escolas públicas, respectivamente. Os cursos de agronomia, farmácia, odontologia, nutrição, fisioterapia e biomedicina também são compostos por uma maioria de alunos provenientes da rede privada.

Em contrapartida, os cursos de educação física, enfermagem, zootecnia, serviço social, tecnologia em radiologia, tecnologia em gestão ambiental e fonoaudiologia possuem um maior número de alunos provenientes da rede pública. Dentre estes, destaca-se o curso de serviço social, no qual o número de alunos provenientes de escolas públicas é 4,35 vezes maior que os alunos provenientes de escolas privadas.

Ao considerar que instituições do ensino superior foram estabelecidas no Brasil para oferecer aos membros de famílias da elite do país acesso a cursos superiores, sendo raros os membros de famílias mais desfavorecidas que conseguiam ter acesso ao mesmo nível educacional (PINHEIRO, 2014), nota-se que a elitização evidente em alguns cursos remete à trajetória histórica do ensino superior brasileiro. Esta desigualdade educacional persistiu por muitos anos, sendo evidenciada pelo fato contraditório das universidades públicas possuírem maior número de alunos oriundos de escolas privadas, cenário de maior divergência ao se considerar alguns cursos específicos. 


\section{A POLÍTICA DE COTAS SOCIAIS PARA O ACESSO AO ENSINO SUPERIOR: O CASO DAS \\ UNIVERSIDADES FEDERAIS MINEIRAS \\ DOI: http://dx.doi.org/10.5007/1983-4535.2017v10n1p256}

Esta análise corrobora para evidenciar a importância das cotas sociais para viabilizar, além do acesso ao ensino superior para este grupo de desfavorecidos, a extinção da elitização que por muito tempo perdurou em determinados cursos. No estudo realizado por Motta e Lopes (2012), estes autores também apontam a dificuldade dos alunos provenientes de escolas públicas ingressarem nos cursos mais concorridos, comumente constituídos por alunos provenientes da rede privada. Nesta realidade relatada, os alunos de escolas públicas são desfavorecidos e submetidos a uma concorrência injusta em virtude do déficit incorrido no ensino básico e médio da rede pública.

Outro aspecto a ser considerado compreende a análise econômica dos formandos. Para tanto, realizou-se o levantamento da renda familiar dos alunos que compõem a amostra (Figura 3).

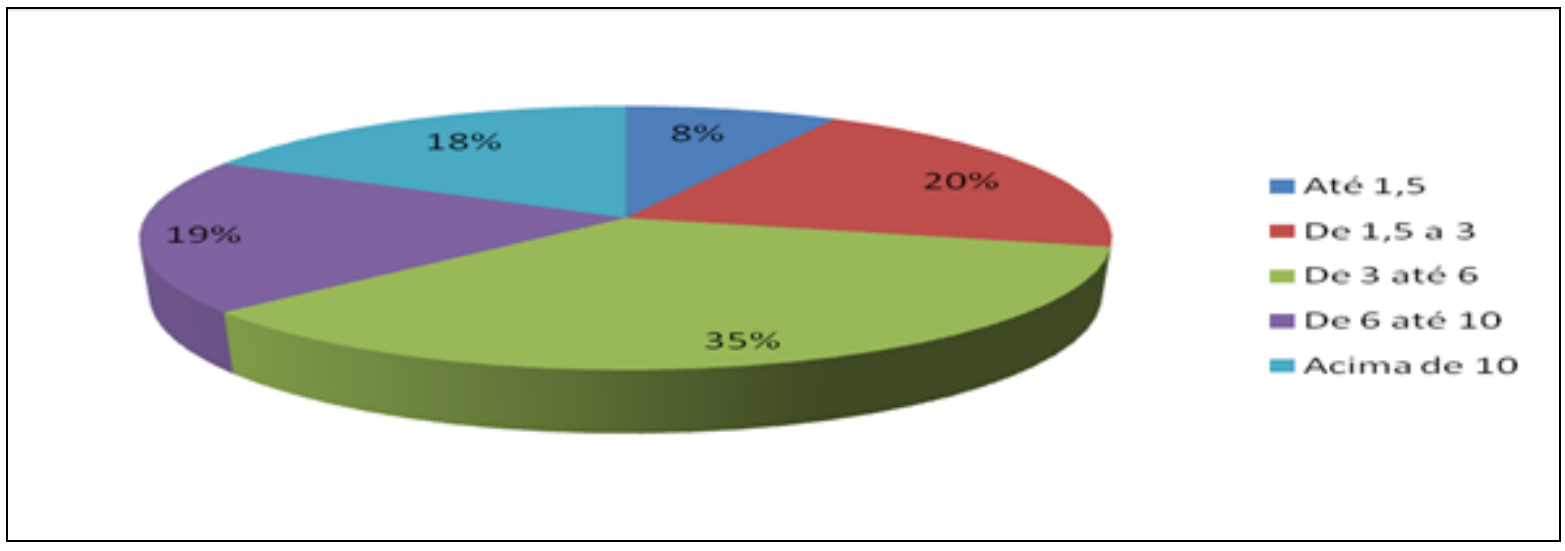

Figura 3 Caracterização da renda dos alunos.

Fonte: Dados da pesquisa, a partir de informações disponíveis na plataforma do INEP.

Nota-se que a maior parte dos formandos possui renda familiar de 3 a 6 salários mínimos. Ademais, identifica-se proximidade no percentual de alunos que possuem renda de 1,5 até 3 salários mínimos, de 6 até 10 salários mínimos e acima de 10 salários mínimos.

No entanto, dentre os 4415 formandos, apenas uma minoria de 371 alunos equivalente a $8 \%$ da amostra - possuem renda familiar de até um salário mínimo e meio. Esta constatação evidencia a dificuldade de alunos de baixa renda ter acesso às instituições públicas de ensino superior, colaborando para ressaltar a importância da adoção das cotas sociais como mecanismo imediato de possibilitar aos indivíduos economicamente desfavorecidos o direito ao ingresso em universidades federais.

Ao alocar os alunos que possuem renda familiar de até um salário mínimo e meio por curso (Quadro2), constatou-se que a presença destes alunos, na maior parte dos cursos, é 


\section{A POLÍTICA DE COTAS SOCIAIS PARA O ACESSO AO ENSINO SUPERIOR: O CASO DAS \\ UNIVERSIDADES FEDERAIS MINEIRAS \\ DOI: http://dx.doi.org/10.5007/1983-4535.2017v10n1p256}

inferior a $20 \%$. Outro aspecto que se destaca nesta análise, consiste no fato de que os cursos de medicina e odontologia, os quais possuem a menor quantidade de alunos provenientes de escola pública, possuem apenas $2 \%$ e $4 \%$, respectivamente, de alunos com a renda considerada na análise.

\begin{tabular}{|l|c|c|c|}
\hline \multicolumn{1}{|c|}{ Curso } & $\begin{array}{c}\mathbf{N}^{\mathbf{0}} \text { de } \\
\text { formandos }\end{array}$ & $\begin{array}{c}\mathbf{N}^{\mathbf{0}} \text { de formandos com renda } \\
\text { familiar de até 1,5 salário }\end{array}$ & $\begin{array}{c}\text { \% de formandos com até } \\
\text { renda familiar de 1,5 salário }\end{array}$ \\
\hline Medicina & 635 & 13 & $2 \%$ \\
\hline Odontologia & 370 & 15 & $4 \%$ \\
\hline Biomedicina & 97 & 5 & $5 \%$ \\
\hline Zootecnia & 207 & 39 & $5 \%$ \\
\hline Farmácia & 494 & 29 & $6 \%$ \\
\hline Medicina veterinária & 441 & 28 & $6 \%$ \\
\hline Fisioterapia & 174 & 15 & $9 \%$ \\
\hline Agronomia & 601 & 56 & $10 \%$ \\
\hline Nutrição & 492 & 47 & $11 \%$ \\
\hline Educação física & 442 & 48 & $12 \%$ \\
\hline Enfermagem & 265 & 33 & $13 \%$ \\
\hline Fonoaudiologia & 8 & 1 & $19 \%$ \\
\hline $\begin{array}{l}\text { Tecnologia } \\
\text { radiologia }\end{array}$ & 32 & 6 & $20 \%$ \\
\hline Serviço social & 133 & 27 & $38 \%$ \\
\hline $\begin{array}{l}\text { Tecnologia em gestão } \\
\text { ambiental }\end{array}$ & 24 & 9 & \\
\hline
\end{tabular}

Quadro 2 Distribuição de alunos de baixa renda por curso.

Fonte: Dados da pesquisa, a partir de informações disponíveis na plataforma do INEP.

Em contrapartida, a presença de alunos de baixa renda é maior nos cursos tecnologia em radiologia, serviço social e tecnologia em gestão ambiental, os quais possuem uma concentração destes alunos de 19\%, 20\% e 38\%, respectivamente. Estes cursos também possuem maior número de formandos provenientes exclusivamente da rede pública de ensino, em relação aos oriundos exclusivamente da rede privada de ensino.

Tais constatações permitem inferir que, antes da Lei 12.711 estabelecer a obrigatoriedade das cotas sociais, os alunos de baixa renda e provenientes da rede pública de ensino buscavam competir por vagas nos cursos menos concorridos, a fim de ampliar suas chances de terem acesso ao ensino superior, em virtude do melhor preparo dos alunos provenientes da rede privada de ensino. Sobre a temática, Rounet (2006) constata que a 
"seleção para a universidade tem se dado, há muito, de forma perversa, privilegiando a condição econômica de seus alunos, mais do que sua qualidade acadêmica" (ROUNET, 2006, p. 8).

Motta e Lopes (2012) destacam o importante papel da educação para possibilitar o pleno desenvolvimento da personalidade humana e reduzir o nível de desigualdade social. Desta forma, destaca-se a importância das cotas sociais como mecanismo imediato para a equidade de acesso ao ensino superior, visto que identificou-se que o número de alunos oriundos de escola pública e com baixa renda é inferior ao número de alunos provenientes de escolas privadas nos cursos analisados. Assim, esta ação afirmativa conferirá aos beneficiados qualificação para se inserir no mercado de trabalho e concorrer a cargos que lhe permitirão atingir a ascensão social.

No entanto, críticos do sistema de cotas argumentam que esta política pode implicar na redução do desempenho institucional. O tópico a seguir direciona-se à análise deste argumento,por meio da realização de dois testes de comparação entre médias. O primeiro teste comparou as notas médias no Enade dos alunos provenientes de escolas públicas e provenientes de escolas privadas. Em seguida, comparou-se as notas médias no Enade de alunos que ingressaram nas universidades federais por meio de cotas por terem estudado em escola pública ou em particular com bolsa e alunos não cotistas.

\subsection{COMPARATIVO ENTRE MÉDIAS}

A adoção do sistema de cotas para o ingresso nas universidades públicas tem gerado controvérsias. Segundo Frias (2012) e Motta e Lopes (2012), um dos argumentos utilizados pelos críticos consiste no fato de que esta modalidade de ação afirmativa ocasiona a redução do desempenho das instituições públicas de ensino superior, em função do ingresso de alunos por meio das cotas sociais.

Com o intuito de analisar a procedência deste argumento, realizou-se um levantamento das notas médias por curso de duas categorias de alunos: os que cursaram todo ensino médio em escolas da rede pública e os que cursaram todo ensino médio em escolas da rede privada de ensino. Para a análise dos dados, primeiramente realizou-se a análise da estatística descritiva dos dados, cujos resultados obtidos são apresentados na Tabela 1. 


\section{A POLÍTICA DE COTAS SOCIAIS PARA O ACESSO AO ENSINO SUPERIOR: O CASO DAS \\ UNIVERSIDADES FEDERAIS MINEIRAS \\ DOI: http://dx.doi.org/10.5007/1983-4535.2017v10n1p256}

Tabela 1 Estatística descritiva dos dados.

\begin{tabular}{lcccccc}
\hline Variável & $\mathbf{N}^{\mathbf{0}}$ de obs & Média & D. Padrão & Mínimo & Máximo & Amplitude \\
\hline Pública & 72 & 55,92 & 6,81 & 38,3 & 73 & 34,7 \\
Privada & 71 & 55,35 & 6,47 & 36,7 & 68,5 & 31,8 \\
\hline
\end{tabular}

Fonte: Dados da pesquisa, a partir de informações disponíveis na plataforma do INEP.

Identifica-se que as médias das duas categorias consideradas são similares, sendo a média dos estudantes de escolas públicas superior em 0,57 pontos à média dos estudantes de escolas privadas. Ademais, ambas as categorias apresentam variabilidade semelhante, visto que a amplitude total de ambas possui valores próximos, sendo 34,7 para a categoria pública e 31,8 para a categoria privada. Corrobora para esta constatação o fato da análise da variabilidade em torno da média de ambas ter apresentado valores semelhantes, visto que o desvio padrão da primeira categoria correspondeu a 6,81 e o da segunda 6,47.

Posteriormente, realizou-se o Teste de Diferença entre Médias, considerando as categorias dos estudantes provenientes de escola pública e dos provenientes de escola privada. Encontrou-se o seguinte resultado (Tabela 2):

Tabela 2 Teste de Diferença entre Médias: pública versus privada.

\section{Resultado Teste de Diferença entre Médias}

\section{(tc) $=0.6643$}

$\mathrm{p}$ valor $=0.5087$

Fonte: Dados da pesquisa, a partir de informações disponíveis na plataforma do INEP.

O teste não rejeitou a hipótese nula de que as médias entre as categorias de estudantes de escola pública e privada são iguais, em virtude do $p$ valor apresentado de 0,5087 . Desta forma, a análise contrapõe o argumento comumente adotado por críticos da política de cotas de que os alunos provenientes de escolas públicas possuem rendimento inferior ao dos estudantes provenientes de escolas privadas.

Frias (2012) aponta em seu estudo que a universidade pública existe com a finalidade primordial de estabelecer a justiça social, compreendida como a igualdade equitativa de oportunidades. Desta forma, apesar da importância da busca pela excelência dos padrões acadêmicos, esta não constitui o principal intento das instituições públicas de ensino superior. Assim, "ainda que ficasse demonstrado que as cotas sociais diminuirão os indicadores acadêmicos e científicos, isso não é suficiente para mostrar que elas são injustas" (FRIAS, 2012, p. 132). 


\section{A POLÍTICA DE COTAS SOCIAIS PARA O ACESSO AO ENSINO SUPERIOR: O CASO DAS

A fim de complementar o estudo, tambémrealizou-se a análise da estatística descritiva de outras duas categorias (Tabela 3). A categoria intitulada "cotistas" designa os alunos que ingressaram na universidade pública por meio das cotas destinadas aos alunos que cursaram todo o ensino médio em escola pública ou em escola privada por meio da concessão de bolsas. Já a categoria "não cotistas", refere-se aos alunos que não utilizaram nenhum tipo de cota para ingressar na universidade pública.

Tabela 3 Estatística descritiva dos dados: cotistas versus não cotistas.

\begin{tabular}{lccccc}
\hline Variável & $\mathbf{N}^{\mathbf{0}}$ de obs & Média & D. Padrão & Mínimo & Máximo \\
\hline Cotistas & 58 & 54,58 & 9,27 & 8,3 & 69,9 \\
Não Cotistas & 73 & 55,76 & 6,04 & 39,7 & 68,5 \\
\hline
\end{tabular}

Fonte: Dados da pesquisa, a partir de informações disponíveis na plataforma do INEP.

A categoria não cotistas contou com 73 observações, visto que todos os cursos considerados na amostra possuem estudantes que ingressaram na universidade sem utilizar o mecanismo de cotas. Em contrapartida, apenas 58 dos cursos ofereceram cotas para alunos que cursaram o ensino médio em escolas públicas ou privadas com bolsa.

Nota-se que as médias das duas categorias consideradas são similares, sendo a média dos estudantes que não utilizaram cotas para ingressar na universidade 1,18 pontos superior à média dos alunos cotistas. No entanto, a amplitude das categorias "cotistas" e "não cotistas" apresentou valores de 61,6 e 29,8, respectivamente. A considerável diferença entre os valores ocorreu em função do valor mínimo dos "cotistas", referente ao curso de serviço social da UFVJM ser de apenas 8,3.

Por possuir a desvantagem de depender apenas de dois valores da distribuição, a amplitude pode ser claramente influenciada por um único valor. Torna-se interessante considerar o desvio padrão, por levar em consideração todos os valores da distribuição. A análise desta medida de dispersão demonstra que ambas as categorias apresentam valores aproximados de variabilidade em torno da média.

Por fim, tambémrealizou-se a comparação entre a média dos estudantes que ingressaram na universidade federal por meio de cotas destinadas aos alunos que cursaram todo o ensino médio em escola pública ou em particular com bolsa e alunos que não utilizaram nenhum tipo de cota. O resultado encontrado está apresentado na Tabela 4. 


\section{A POLÍTICA DE COTAS SOCIAIS PARA O ACESSO AO ENSINO SUPERIOR: O CASO DAS \\ UNIVERSIDADES FEDERAIS MINEIRAS \\ DOI: http://dx.doi.org/10.5007/1983-4535.2017v10n1p256}

Tabela 4 Teste de Diferença entre Médias: cotistas versus não cotistas.

Resultado Teste de Diferença entre Médias

(tc) $=-0.9926$

$\mathrm{p}$ valor $=0.3251$

Fonte: Dados da pesquisa, a partir de informações disponíveis na plataforma do INEP.

O segundo teste realizado também não rejeitou a hipótese nula de que as médias entre os alunos cotistas e não cotistas são iguais, em virtude do $p$ valor apresentado de 0,3251 . Demonstra-se que não há uma diferença estatisticamente significativa entre as médias. Desta forma, o desempenho dos alunos que ingressaram na universidade pública por meio da política de cotas não é inferior ao desempenho dos alunos provenientes da rede particular de ensino. Logo, a inclusão de alunos por meio de cotas sociais em universidades públicas não implica na redução do desempenho desta modalidade de instituições.

A comparação entreo rendimento acadêmico de alunos cotistas e não cotistas já foi analisada por Rouanet (2006). Em seu estudo, o autor concluiu que apesar dos alunos cotistas apresentarem um desempenho ligeiramente inferior no vestibular, no decorrer dos cursos essa diferença é igualada ou superada. Destaca-se que o resultado encontrado pelo autor converge com o resultado encontrado neste estudo.

Assim, demonstrou-se que o desempenho nos cursos superiores de alunos provenientes de escolas públicas e privadas, e cotistas e não cotistas, não possuem diferenças estatisticamente significativas. Identifica-se, desta forma, que as críticas que consideram a concessão de cotas sociais um fator negativo para o desempenho das instituições não são justificáveis. Esta constatação contribui para enfatizar a importância da adesão da política de cotas sociais como uma ação imediata adotada para fornecer aos desfavorecidos economicamente o direito à educação superior e reduzir as desigualdades sociais existentes.

\section{CONCLUSÕES}

A educação superior no Brasil atualmente está vivenciando um momento de transição no que tange a política de acesso às IFES, em virtude da Lei $\mathrm{n}^{\circ} 12.711 / 2012$, sancionada em agosto de 2012, que será aplicada progressivamente até o ano de 2016. Neste sentido, tem-se incitado novas discussões no âmbito acadêmico e da sociedade em geral, questionando qual o impacto da adoção da política de cotas sociais no acesso às universidades federais e no desempenho acadêmico destas instituições. A fim de avaliar tais aspectos, o presente estudo considerou como unidades de análise as universidades federais mineiras. Para tanto, utilizou 


\section{A POLÍTICA DE COTAS SOCIAIS PARA O ACESSO AO ENSINO SUPERIOR: O CASO DAS

os dados provenientes do Enade, atual mecanismo de avaliação do desempenho discente no ensino superior, em sua edição de 2013.

Alcançou-se o propósito definido de discutire analisar aspectos socioeconômicos dos formandos das universidades federais mineiras no ano de 2013 que realizaram o Enade, por meio da realização de uma análise descritiva para caracterizar o grupo de formandos do ano de 2013. Identificou-se que o número de alunos oriundos de escola pública e com baixa renda é inferior ao número de alunos provenientes de escolas privadas nos cursos analisados, principalmente no que tange aos cursos mais concorridos.Evidencia-se, desta forma, a importância das cotas sociais, visto que o acesso de estudantes de escolas públicas e de baixa renda é relativamente pequeno nas universidades federais.

Além disso, os resultados demonstraram que não há diferença estatisticamente significativa entre o desempenho dos estudantes provenientes exclusivamente de escolas públicas e dos provenientes exclusivamente de escolas privadas,e entre os estudantes cotistas e não cotistas. Demonstra-se assim que, mesmo com a deficiência existente no ensino fundamental público brasileiro, o desempenho dos estudantes provenientes de escolas públicas equipara-se ao dos estudantes provenientes de escolas privadas, após ambos receberem um ensino equitativo. Tal fato reitera a relevância das políticas de acesso ao ensino superior.

Por fim, a limitação deste trabalho refere-se à utilização das notas do ENADE apenas do ano de 2013, não compreendendo, deste modo, todos os cursos existentes nas IFES mineiras. Tal fato é resultante da própria característica do exame que não avalia todos os cursos em todos os anos. Para futuras pesquisas, sugere-se a análise dos cursos não compreendidos neste estudo, assim como esforços para avaliar a política de cotas posteriormente à sua completa implementação.

\section{REFERÊNCIAS}

BELLO, E. Políticas de ações afirmativas no Brasil: uma análise acerca da viabilidade de um sistema de cotas sociais para ingresso nas universidades. Revista Direito, Estado e Sociedade. Rio de Janeiro: PUC-Rio, n. 26, p. 32-53, jan./jul., 2005.

BEZERRA, T. O. C.; GURGEL, C. A política pública de cotas em universidades, desempenho acadêmico e inclusão social. Sustainable Business InternationalJournal, n. 9, p. 1-22, 2011. 
BRANDÃO, C. F. As cotas na universidade pública brasileira: será esse o caminho? Campinas, SP: Autores Associados. Coleção polêmicas do nosso tempo, 2005, v. 92.

BRASIL, Constituição da República Federativa do Brasil (1988). Brasília, Senado Federal. Disponível em:

$<$ http://www.planalto.gov.br/ccivil_03/constituicao/constitui\%C3\%A7ao.htm> acesso em: 12 de abril de 2015.

BRASIL. Lei $\mathbf{n}^{\mathbf{0}} \mathbf{1 2 . 7 1 1}$, de 29 de agosto de 2012. Dispõe sobre o ingresso nas universidades federais e nas instituições federais de ensino técnico de nível médio. Disponível em: $<$ http://www.planalto.gov.br/ccivil_03/_ato2011-2014/2012/lei/112711.htm>. Acessoem: 6 deabril. de 2014.

CROSBY, F. J.; CORDOVA, D. I. Words worth of widsdom: toward an understanding of affirmative action. Journal of Social Issues, [S.1.], v. 52, n. 4, p. 33-49, 1996.

FRIAS, L. As cotas raciais e sociais em universidades públicas são injustas? Revista Direito, Estado e Sociedade, n. 41, 2014.

GOMES, J. B. Ação afirmativa \& princípio constitucional da igualdade: o direito como instrumento de transformação social. A experiência dos EUA. Rio de Janeiro: Renovar, 2001.

INSTITUTO NACIONAL DE ESTUDOS E PESQUISAS EDUCACIONAIS ANÍSIO TEIXEIRA - INEP. Relatórios de cursos. ENADE 2013. Disponível em:

$<$ http://enadeies.inep.gov.br/enadeIes/enadeResultado/>. Acessoem: 07 defevereiro de 2015.

JONES, J. E. The rise and fall of affirmative action. In: HILL, H; JONES, J. (Ed.). Race in American: the struggle for equality. Madison: University of Wisconsin, 1993. p. 345-369.

LAGO, J.; MALBOUISSON, C.; SILVA, V. F.; CAVALCANTI, I. Cotas e desempenho na Universidade Federal da Bahia: uma análise dos ingressantes de 2010 a 2012. In: X Encontro de Economia Baiana, 2014, Universidade Federal da Bahia, Salvador, BA.

LEITE, L. J. Política de cotas no Brasil: política social? Revista Katál, Florianópolis., v. 14, n. 1, p. 23-31, jan./jun. 2011.

MACHADO, C. S.; MAGALDI, C. A. Sistema de cotas, equidade e assistência estudantil. In: XIV COLÓQUIO INTERNACIONAL DE GESTÃO UNIVERSITÁRIA - CIGU, 2014, Universidade Federal de Santa Catarina, Santa Catarina, SC.

MOEHLECKE, S. Ação afirmativa: história e debates no Brasil. Cadernos de Pesquisa, $\mathrm{n}$. 117 , p. 197-217, novembro/2002.

MOTTA DA, I. D.; LOPES, H. M. O sistema de cotas sociais para ingresso na universidade pública. Revista do Instituto do Direito Brasileiro, n. 11, p. 6823-6857, 2012.

PINHEIRO, J. S. S. P. Desempenho acadêmico e sistema de cotas: um estudo sobre o rendimento dos alunos cotistas e não cotistas da Universidade Federal do Espírito Santo. 
2014. 101 f. Dissertação (Mestrado em Gestão Pública) - Programa de Pós Graduação em Gestão Pública do Centro de Ciências Jurídicas e Econômicas, Universidade Federal do Espírito Santo, Vitória. 2014.

ROESH, S. M. A. Projetos de estágio e de pesquisa em administração. 2. ed. São Paulo: Atlas, 1999.

ROUANET, L. P. John Rawls e a política de ações afirmativas. Disponível em: $<$ http://br.oocities.com/eticaejustica/politicasafirmativas.pdf $>$. Acesso em 12 de maio de 2015 às $10 \mathrm{~h} 44 \mathrm{~min}$.

SILVA, P. B.; S. P. Representações sociais de estudantes universitários sobre cotas na universidade. Fractal, Revista de Psicologia, v. 24, n. 3, p. 525-542, Set./Dez. 2012.

WITTE, R. S., WITTE, J.S. Estatística. 7 ed. Rio de Janeiro: LTC, 2005. 